\title{
O TRIBUNAL PENAL INTERNACIONAL: UMA ANÁLISE SOBRE SUA EVOLUÇÃO E SUA COMPETÊNCIA PARA JULGAR O CRIME PELO TERRORISMO
}

\section{THE INTERNATIONAL CRIMINAL COURT: AN ANALYSIS OF ITS EVOLUTION END ITS COMPETENCE TO JUDGE THE CRIME OF TERRORISM}

\author{
${ }^{1}$ Susana Camargo Vieira \\ ${ }^{2}$ Ana Maria de Andrade
}

\section{RESUMO}

O conjunto normativo e institucional do Direito Internacional Penal desenvolveu-se substancialmente a partir no início do século XX, com o tratado de Versalhes; consolidou-se com a constituição dos Tribunais de Nuremberg e Tóquio e dos Tribunais ad hoc para Ruanda e para a ex-Iugoslávia, até culminar na criação do Tribunal Penal Internacional TPI. O TPI é um Tribunal Penal Internacional de caráter permanente, criado com o propósito maior de contribuir para a preservação da paz e da segurança no planeta, além de pôr fim à impunidade dos responsáveis por crimes mais graves que afetam a comunidade internacional. É atribuída ao TPI a competência para julgar quatro categorias de crimes: contra a humanidade; de genocídio; crimes de guerra e de agressão. As perguntas que hoje se levantam são: não obstante os incontestáveis avanços, há que se levantar a necessidade de revisão de sua competência material para incluir, entre os antes citados, o crime de terrorismo, hoje percebido como grande ameaça à paz e à segurança da humanidade? A segunda pergunta vai além. Por suas características, há quem defenda que este crime se enquadre na categoria de crimes contra a humanidade (devendo, portanto, ser incluído no rol relativo aos crimes desta natureza, previstos no art. $7^{\circ}$ do instrumento constitutivo do Tribunal Penal Internacional, o Estatuto de Roma); seria este o caminho? $O$ tema foi escolhido para esse trabalho em função de sua inegável importância para a Sociedade Internacional tanto quanto para os Estados que a compõem, no momento em que nenhum Estado parece estar a salvo da ameaça desse flagelo. Para estudar a evolução das questões adotou-se o método de pesquisa bibliográfica e jurisprudencial, aliado ao método crítico.

Palavras-chave: Tribunal penal internacional, Evolução, Competência material, Crimes contra a humanidade, Terrorismo

\begin{abstract}
The normative and institutional framework of International Criminal Law has developed substantially since the first steps given in the Treaty of Versailles; the constitution of the courts of Nuremberg and Tokyo, the ad hoc Tribunals for Rwanda and for the former Yugoslavia were consolidating steps in the process, which culminated in the creation of the International Criminal Court, the ICC. The ICC is a permanent international judicial court, created for the greater purpose of contributing to the preservation of world peace and security by putting an end to the impunity of those responsible for more serious crimes affecting the international community. It has been assigned the competence to judge four categories of crimes: crimes against humanity; genocide; war crimes and the crime of aggression. The questions now raised are: despite its undeniable advancing, is there a need to question and

\footnotetext{
${ }^{1}$ Doutora em Direito pela Universidade de São Paulo - USP, São Paulo, SP, Brasil. Professora na Fundação Universidade de Itaúna, FUIT, Minas Gerais, Brasil. E-mail:

${ }^{2}$ Mestranda em Direito pela Fundação Universidade de Itaúna - FUIT, Minas Gerais, MG, Brasil. Advogada. Email:
} 
review its substantive jurisdiction to include jurisdiction over the crime of terrorism? The second question digs further: given its characteristics, there are those who argue that this crime fits into the category of crimes against humanity. Should this, therefore, be included in the list concerning crimes of this nature, referred to in art. 7 of the Rome Statute, (constitutional instrument of the International Criminal Court)? The subject was chosen in view of its undeniable importance to the International Society as well as sovereign states, in a moment in which no State, nor the International Society, seems to be free of threat from this horror. The method adopted was that of bibliography and jurisprudence review, associated to the critical method.

Keywords/Palabras-claves/Mots-clés: International criminal court, Evolution, Substantive competence, Crimes against humanity, Terrorism

\section{INTRODUÇÃO}

O processo de construção e solidificação do Direito Internacional, no que diz respeito aos meios de solução de controvérsias, aconteceu de forma mais incisiva a partir do século $\mathrm{XX}$, especialmente pelo crescimento da interdependência entre os Estados. Em se tratando de conciliar os interesses de Estados soberanos, muitos são os conflitos e dificuldades encontrados pela impossibilidade da imposição de normas e medidas de coerção e execução sem a anuência dos próprios destinatários de tais normas, que, invariavelmente temem pela perda ou diminuição de seu poder e autonomia, fator que se apresentava como um obstáculo para a eficácia do próprio Direito Internacional (AMARAL JÚNIOR, 2008).

No final do século XIX e especialmente a partir do início do século XX, começaram a despontar as principais transformações nos meios de solução de controvérsias rumo a sua institucionalização, dentre elas a constituição de cortes judiciais, que trouxeram consigo nova perspectiva para este ramo do Direito (AMARAL JÚNIOR, 2008).

No âmbito do Direito Internacional Penal, que mais interessa a esse estudo, o avanço de seu conjunto normativo e institucional encontra etapa importante no tratado de Versalhes, criado em1919, que introduziu o conceito de responsabilização penal individual e apontou para a necessidade da criação de um órgão de jurisdição penal competente para julgar crimes de relevância internacional; mas sua efetiva concretização se deu a partir da constituição dos Tribunais de Nuremberg e Tóquio, passando pelos Tribunais ad hoc para Ruanda e para a exIugoslávia criados pelo Conselho de Segurança da ONU, culminando com a criação Tribunal Penal Internacional em1998 (GARCIA, 2012).

O Tribunal Penal Internacional, conforme veremos no decorrer do trabalho, representou incontestável avanço para o Direito Internacional Penal; escapou ao âmbito de 
sua competência material, todavia, a apreciação e julgamento do crime de terrorismo, por não ter sido considerado à época de constituição daquela corte judiciária suficientemente relevante para ser submetido à sua apreciação.

Não seria esse o caso, provavelmente, se o assunto estivesse sendo discutido hoje. $\mathrm{O}$ tema foi escolhido para esse trabalho justamente pela importância que o problema assumiu - e que não para de crescer - no contexto de ameaças à paz e segurança internacionais. O objetivo deste estudo é, a partir de análise da evolução do tema no Direito Internacional Penal, identificar avanços e insuficiências - especialmente quanto à competência material do Tribunal Penal Internacional para apreciar um crime (o de terrorismo) que vem assombrando (e impondo um constante estado de insegurança) a humanidade, buscando, ao mesmo tempo, analisar sua possível identificação com os crimes contra a humanidade (que viabilizaria o julgamento e punição dos mentores e praticantes deste crime pelo Tribunal Penal Internacional).

Nesse sentido, recorrendo-se ao método de pesquisa bibliográfica, documental e jurisprudencial, busca-se em um primeiro momento recordar os acontecimentos e precedentes que levaram à criação do TPI; em um segundo, passa-se a uma breve apreciação e contextualização do próprio TPI (processo de implementação); em seguida aborda-se mais especificamente a questão da competência ratione materiae do TPI, conforme o Estatuto de Roma, indagando-se sobre a possibilidade de incluir o crime de terrorismo no rol daqueles previstos no artigo $7^{\circ}$ do Estatuto de Roma. Finalmente, na conclusão, procura-se responder às perguntas feitas nesta Introdução.

\section{A EVOLUÇÃo dA QUESTÃo NO DIREITO PENAL INTERNACIONAL: DE NUREMBERG À HAIA}

Após anos de consenso na comunidade internacional sobre a inimputabilidade de governantes ou militares pela prática de crimes durante períodos de guerra, essa máxima finalmente começou a se modificar a partir da Primeira Guerra Mundial (SANDS, 2003), que vitimou mais de 15 milhões de pessoas, além do extermínio de cerca de um milhão de armênios, perpetrado pelo Império Turco-Otomano em 1915 (LEWANDOWSKI, 2002). Com o fim da Primeira Grande Guerra as potências vencedoras manifestaram a disposição de punir individualmente os responsáveis pelas atrocidades cometidas durante as ações bélicas, conforme ficou registrado no Tratado de Versalhes. ${ }^{1}$ 
Mas o conceito de responsabilização penal individual de criminosos de guerra, introduzido pelo Tratado de Versalhes, somente concretizou-se com a instituição dos tribunais de Nuremberg e Tóquio, após a Segunda Guerra Mundial, quando mais de 55 milhões de pessoas morreram, vítimas das barbáries do conflito (LEWANDOWSKI, 2002).

\subsection{OS TRIBUNAIS DE NUREMBERG}

Em 1943, ainda no transcurso da guerra, as potencias aliadas (Estados Unidos, União Soviética e Reino Unido) já manifestaram a disposição em julgar e punir as atrocidades perpetradas pelos criminosos do Eixo, tão logo cessasse o conflito, através do documento que ficou conhecido como a Declaração de Moscou (CARDOSO, 2012).

Após a rendição da Alemanha, que se deu em maio de 1945, foi constituído o primeiro Tribunal Militar Internacional (o de Nuremberg2), cujo estatuto foi aprovado e assinado em 8 de agosto de 1945, na cidade de Londres, pelas potências aliadas mais a França e, subsequentemente, por outros 19 estados (GARCIA, 2012). Esse instrumento constitutivo parametrizou a atuação do órgão, estabelecendo a sua forma de funcionamento bem como a extensão de sua competência, dentre outras disposições, tendo sido endossado pela Assembléia Geral da ONU através da Resolução 95 (I), de 11 de dezembro de 1946 (CRAWFORD, 2003; In SANDS, 2003).

Foram definidas, com base em condutas já consideradas ilícitas no âmbito do Direito Internacional, três categorias de crimes que deveriam ser apreciadas pelo recém-criado tribunal, quais sejam, crimes contra a paz (planejamento, preparação, desencadeamento ou execução de guerra de agressão), crimes de guerra (violação das leis e costumes de guerra previstas na Convenção de Haia de 1907 e Convenção de Genebra de 1929) e crimes contra a humanidade (o assassinato, o extermínio, a redução à escravidão, a deportação e outros atos desumanos cometidos contra qualquer população civil, antes ou durante a guerra; ou perseguições por razões políticas, raciais e religiosas) (GARCIA, 2012).

\footnotetext{
${ }^{1}$ O Tratado de Versalhes, assinado em 28 de junho de 1919 para fazer cessar a primeira Guerra Mundial, previa em seu art. 227 a constituição de uma corte especial para processar e julgar o Kaiser Guilherme II acusado de ter iniciado a $1^{a}$ Guerra Mundial, todavia, isso não foi possível já que os Países Baixos, onde encontrava-se exilado o Kaiser, negaram-se a entregá-lo para julgamento sob a alegação de que o crime por ele cometido era de natureza política (CARDOSO, 2012). Ademais, o retromencionado documento previa em seus artigos 228 e 229 o julgamento de militares alemães por tribunais dos aliados, fato que também não se concretizou, tendo a Alemanha promulgado uma lei conferindo à sua Suprema Corte a competência para efetivar os referidos artigos. (GARCÍA, 2012)
} 
O julgamento dos acusados militares durou quase um ano e terminou com a condenação de quinze pessoas (onze penas de morte e quatro de prisão perpétua) e três absolvições (CASELLA; ACCIOLY; SILVA, 2010).

A grande contribuição da criação deste tribunal foi, indubitavelmente, a previsão no artigo $7^{\circ}$ de seu estatuto da punição individual dos acusados, não importando a posição ou cargo por eles ocupado, sendo refutada a alegação de que os crimes haviam sido cometidos em nome do Estado ou em obediência a ordem superior (GARCIA, 2012).

Não obstante as reconhecidas contribuições desta inovação, críticas também foram suscitadas pelos doutrinadores, dentre as quais a da falta de imparcialidade em julgamentos que recairiam somente sobre os vencidos, e, por serem efetuados pelos vencedores constituirse-iam em uma espécie de Tribunal de Exceção - além sua natureza post factum, ou seja, contrariando o princípio da anterioridade da lei, retroagindo no tempo em desfavor dos acusados. Dessa última crítica, os aliados se defenderam alegando terem se baseado em leis e normas internacionais preexistentes e vigentes para a definição dos crimes (CARDOSO, 2012).

\subsection{O TRIBUNAL DE TÓQUIO}

Um pouco mais tarde, após a rendição do Japão que aconteceu em setembro de 1945, posteriormente à rendição da Alemanha, foi instituído o Tribunal de Tóquio em 19 de janeiro de 1946, para julgamento dos crimes cometidos no Extremo Oriente. Os padrões foram semelhantes àqueles adotados pelo Tribunal de Nuremberg, inclusive quanto à competência material. A diferença apresentada em relação ao seu precursor foi que a posição hierárquica ocupada pelos acusados poderia servir de atenuante para a pena, dado o caráter imperialista do Japão que impunha, política e moralmente, o dever de obediência às ordens superiores (GARCIA, 2012). Dos julgamentos do Tribunal de Tóquio resultaram vinte e oito condenações, sendo que sete acusados foram apenados com a morte, dezesseis foram condenados à prisão perpétua e os demais a penas mais brandas (CASELLA; ACCIOLY; SILVA, 2010) e sua instituição foi objeto das mesmas críticas do seu precursor.

\footnotetext{
$\overline{2} \mathrm{Na}$ realidade, os crimes imputados aos alemães foram julgados por tribunais diferentes, na cidade alemã de Nuremberg, que lhes deu o nome geral. Os Julgamentos de Nuremberg duraram anos e se encerraram em 1948, já em plena Guerra Fria, depois do Bloqueio de Berlim pela União Soviética. Um filme que merece ser visto é Judgement at Nuremberg, com Spencer Tracy, em branco e preto, e que se refere ao julgamento dos juízes alemães.
} 
A instituição desses tribunais, além de evitar a impunidade dos grandes criminosos de guerra, tornou-se o marco inaugural da responsabilização penal individual por infringência a normas internacionais e seu processamento por instâncias judiciais internacionais. E nisto residiu seu grande legado para a construção do Direito Penal Internacional.

\subsection{O TRIBUNAL PENAL INTERNACIONAL AD HOC DA EX-IUGOSLÁVIA}

Mais recentemente, na década de 90 do século XX, o mundo assistiu a novas séries de graves violações cometidas contra o direito internacional humanitário e os direitos humanos, ocorridas na região da ex-Iugoslávia e em Ruanda, que demandaram uma atuação incisiva e efetiva do Conselho de Segurança da das Nações Unidas. Após o insucesso nas tentativas de restabelecimento da paz em ambos os conflitos, o órgão de segurança da ONU viu-se compelido a uma atitude que respondesse às expectativas da comunidade internacional, determinando nesse período a criação de dois tribunais penais ad hoc, ou seja, de caráter temporário, para julgar os criminosos responsáveis pelos crimes cometidos nesses dois conflitos. A atitude do CSNU representou um avanço importante na atuação do órgão (CARDOSO, 2012).

$\mathrm{Na}$ região da Ex-Iugoslávia, de extenso território e grandes diferenças étnicas e religiosas, eclodiu, no início da década de 90, um conflito de grandes proporções, em que predominantemente $^{3}$ os sérvios foram responsáveis pela prática de crimes atrozes, especialmente na região da Bósnia, tais como crimes de guerra, tentativas de depuração étnica e violações do direito internacional humanitário (CARDOSO, 2012). Através da Resolução 808 de 1993, o Conselho de Segurança determinou a criação do Tribunal Penal Internacional para a ex-Iugoslávia, baseado no art. 39 da Carta da ONU, para fazer cessar o conflito e punir os seus responsáveis. Subsequentemente, através da Resolução 827 de 1993 fundamentada, por orientação do Secretário Geral, no Capítulo VII do estatuto da Carta da ONU (que dispõe sobre os casos de ameaça e ruptura da paz e ato de agressão), o estatuto do órgão judicial foi aprovado (AMARAL JÚNIOR, 2008).

O Tribunal Penal Internacional para a ex-Iugoslávia ainda está em funcionamento em Haia (Países Baixos) ${ }^{4}$ e sua competência em razão da matéria recaiu sobre os crimes contra o direito internacional humanitário (AMARAL JÚNIOR, 2008) que é o "conjunto de normas que busca limitar os efeitos dos conflitos armados; protege as pessoas que não participam ou que deixaram de participar das hostilidades e restringe os meios e métodos de guerra" (CICV, 2015). 


\subsection{O TRIBUNAL PENAL INTERNACIONAL $A D$ HOC SOBRE RUANDA}

Em 1994, o mundo assistiu a mais um capítulo trágico de sua história com a deflagração de uma verdadeira guerra civil em Ruanda, na África, motivada por conflitos de natureza étnica entre hutus (maioria) e tutsis (minoria) vitimando quase um milhão de pessoas (CARDOSO, 2012). A solução adotada pelo Conselho de Segurança da ONU foi semelhante àquela adotada por ocasião dos conflitos na ex-Iugoslávia. Através da Resolução 955 de 8 de novembro de 1994, foi criado, pelo Conselho de Segurança o segundo tribunal ad hoc: o Tribunal Penal Internacional para Ruanda, com os mesmos objetivos do primeiro, quais sejam, fazer cessar o conflito e punir os seus responsáveis. A fundamentação para sua criação também se baseou no Capítulo VII da Carta da ONU (AMARAL JÚNIOR, 2008).

O local designado para sediar o Tribunal Penal Internacional para Ruanda ${ }^{5}$ foi a cidade de Arusha, capital da Tanzânia e sua competência material abrangia o crime de genocídio e os crimes de lesa-humanidade (AMARAL JÚNIOR, 2008).

Aos tribunais penais ad hoc foi atribuída competência restrita do ponto de vista temporal (crimes praticados a partir de 1991 na ex-Iugoslávia e no ano de 1994 em Ruanda) e territorial (em territórios daqueles países, sendo que em Ruanda abarcou os crimes de cidadãos ruandeses em Estados vizinhos, já que eles muitas vezes perseguiam e vitimavam refugiados nesses locais). Ambos acolheram em seus estatutos princípios de Direito Humanitário, como e a exclusão da pena de morte e de trabalhos forçados, além do princípio do non bis in idem (informador do Direito Penal e que veda a repetição de punição individual pelo mesmo fato) e determinaram a primazia do órgão para os julgamentos em relação aos tribunais nacionais (GARCIA, 2012).

Apesar das críticas suscitadas contra a instituição destes tribunais ad hoc, como a ilegitimidade do Conselho de Segurança da ONU para instituí-los ${ }^{6}$ (crítica esta rebatida pela fundamentação jurídica das resoluções na função atribuída ao órgão de segurança da ONU através do art. 39 de seu estatuto, que o incumbe de assegurar a manutenção da paz), além de sua natureza post factum (GARCIA, 2012), há que se reconhecer um avanço em relação aos tribunais de Nuremberg e Tóquio, já que, no caso da ex-Iugoslávia e Ruanda não se tratou de

\footnotetext{
${ }^{3}$ Mas não exclusivamente. Na realidade, o primeiro julgamento (o de Tadic) foi de um croata.

${ }^{4}$ Vide <http://www.icty.org/> para todo tipo de informação, histórica e atualizada.
} 
tribunais constituídos por vencedores para julgar vencidos. Além disso, a criação desses tribunais abriu importante precedente para o julgamento de pessoas que praticam delitos em conflitos internos, mas que têm relevância internacional e evidenciou a necessidade de um órgão permanente de justiça no âmbito do Direito Penal Internacional, impulsionando os debates e esforços para sua criação.

Elio Cardoso resume bem o momento em que o projeto de criação do Tribunal Penal Internacional ganha força e os motivos impulsionadores da iniciativa de sua implantação por parte dos Estados:

\begin{abstract}
O projeto do TPI ganhou maior factibilidade na medida em que a corrente majoritária dos países parecia se convencer das aparentes vantagens de estabelecer uma instituição em bases permanentes, constituída por meio de tratado internacional e dotada de competência geral, que não se limitasse a contexto geográfico ou a situações específicas. Na eventualidade de um novo genocídio, por exemplo, que demandasse a atuação de um órgão penal internacional, seria preferível contar com um tribunal permanente, que já deveria estar em plenas condições de atuar, de modo mais célere e menos custoso, do que com um órgão que teria de ser estabelecido após a ocorrência dos crimes. As vantagens de natureza institucionais também pareceriam presentes, até mesmo no sentido de minimizar os questionamentos jurídicos e de aumentar a sua efetividade. Por essas razões, foi desencadeado um movimento em direção a um TPI. (CARDOSO, 2012, p. 34)
\end{abstract}

\title{
2. FINALMENTE, O TPI.
}

Assim, após muitos debates e inspirado na evolução do Direito Penal Internacional desde a criação do Tribunal de Nuremberg e nos clamores da comunidade internacional, nasce o Tribunal Penal Internacional - TPI, através do Estatuto de Roma, aprovado pela Conferência de Plenipotenciários em 1998 (Conferência de Roma), e que entrou em vigor em 2002. (AMARAL JÚNIOR, 2008). O Tribunal Penal Internacional é uma instituição permanente, com sede na Haia (Países Baixos), dotada de personalidade jurídica internacional. Sua criação representa um divisor de águas no Direito Penal Internacional, e consolida o indivíduo como sujeito e destinatário do Direito Internacional $^{7}$ e não mais como objeto, consagrado o princípio da responsabilidade penal internacional individual (LIMA; BRINA, 2006). Suas características e princípios adotados demonstram o amadurecimento e evolução em relação aos tribunais que o antecederam.

A principal característica do TPI é ser informado pelo Princípio da Complementaridade, previsto no art. $1^{\mathrm{o}}$ de seu instrumento constitutivo (BRASIL, 2002), segundo o qual, nas palavras de Alberto do Amaral Júnior (2008, p. 260) “A ação do Tribunal é, portanto, esporádica e excepcional e cobre as hipóteses em que há incapacidade ou falta de 
disposição dos Estados em processar e julgar os responsáveis" - o que significa dizer, em outras palavras, que a primazia para investigar, processar e julgar os crimes de competência do TPI é dos próprios Estados, diferentemente do que aconteceu nos tribunais antecessores. Esse dispositivo contribui para reforçar as jurisdições internas na medida em que permite aos Estados assumirem a responsabilidade de julgar seus criminosos, mas, ao mesmo tempo, deixa claro que omissões serão supridas pela Corte Internacional. Desta feita, pressupõe-se que os Estados envidarão esforços para fazê-lo, sob pena de deixarem transparecer qualquer sinal de incompetência ou mesmo conivência com atos contrários às normas gerais de proteção ao ser humano no âmbito internacional.

Outros princípios importantes adotados pelo TPI, balizadores de sua atuação, são: a) nullum crimen sine lege (veda o uso de analogia na interpretação de normas definidoras de crimes e determina a aplicação da regra do in dubio pro reo), b) nulla poena sine lege, previstos no artigo 23 do Estatuto de Roma (BRASIL, 2002), determinando que não há crime nem pena sem lei anterior que os defina. Este também representa importante avanço em relação aos tribunais do passado, já que determina que os acusados só possam responder por crimes e serem punidos dentro dos limites e disposições preestabelecidas no estatuto.

O TPI recepcionou ainda outros princípios gerais informadores do Direito Penal, tais como, não retroatividade ratione personae (anterioridade da lei - art. 24), da responsabilidade individual (art. 25), do ne bis in idem (ninguém pode ser punido mais de uma vez pelo mesmo crime - art. 20) (BRASIL, 2002).

No que diz respeito à sua competência, esta é delimitada (BRASIL, 2002):

a) ratione loci: em razão do local - limitada espacialmente ao território de qualquer Estado parte ou ao território de Estado-não Parte se houver acordo específico, conforme disposto do artigo 4.2 (todavia o tribunal será competente para julgar crime praticado em qualquer território do mundo na hipótese de denúncia pelo Conselho de Segurança, conforme artigo 12.2 c/c 13, alínea b);

b) ratione temporis: temporalmente - a partir da entrada em vigor do Estatuto (para os Estados que o ratificarem após a sua entrada em vigor, a competência se dará a partir da ratificação, salvo se o Estado declarar seu consentimento em que o Tribunal exerça a sua competência em relação ao crime em questão anterior à ratificação, conforme art. $11.2 \mathrm{c} / \mathrm{c}$ $12.3)$;

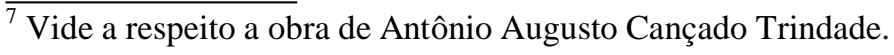


c) ratione personae: em razão da pessoa do acusado - o TPI terá competência para julgar pessoas físicas, naturais, de acordo com os artigos 1 e 25.1 (excluindo-se portanto, Estados e Organizações Internacionais), maiores de 18 anos (artigo 26), nacionais de Estado parte ou nacionais de Estado não parte que pratiquem crimes em território de Estado parte (artigo 12, parágrafos 2 e 3), prescindindo o atendimento à estas condições em caso de denúncia pelo Conselho de Segurança (artigo 12.2 c/c 13, alínea b) e

d) ratione materiae: em razão da matéria - de acordo com o art. 5.1 a competência do Tribunal limita-se aos "crimes mais graves, que afetam a comunidade internacional no seu conjunto", sendo eles divididos em quatro categorias (crime de genocídio, crimes contra a humanidade, crimes de guerra e crime de agressão), que serão abordadas mais detalhadamente em capítulo próprio do presente estudo.

A aceitação de sua jurisdição é automática e não admite reservas (art. 12.1) (BRASIL, 2002), ou seja, pela ratificação do Estatuto do TPI, o Estado aceita, independentemente de consentimento expresso nesse sentido, a jurisdição do tribunal ao mesmo tempo em que não pode fazer reservas a determinadas matérias, devendo se submeter à jurisdição do órgão em relação a todos os crimes de sua competência.

Embora o TPI não possa ainda ser definido como uma instituição de caráter universal, e esta seja, por enquanto, uma aspiração, já que não abrange todo o território do globo terrestre pela recusa à sua ratificação por parte de alguns Estados da comunidade internacional, dentre os quais importantes potências mundiais como China, Estados Unidos e Rússia (CARDOSO, 2012), um traço importante que o diferencia dos tribunais antecessores é o fato de não ter sido criado para uma situação singular, específica, em área territorial determinada, fato que lhe confere maior legitimidade.

A independência também foi uma característica marcada em seu instrumento constitutivo. A esse respeito, Elio Cardoso bem lembra que:

Como a sua atuação se daria em ambiente inevitavelmente político, o imperativo da independência da Corte diante das pressões políticas afigurar-se-ia fundamental. Ao longo do processo negociador, uma das preocupações era resguardar a instituição da influência de atores políticos ou pelo menos minimizar a possibilidade de que os trabalhos da instituição ficassem à mercê de fatores políticos. (CARDOSO, 2012, p. 40)

Nesse sentido, alguns cuidados foram tomados visando preservar a sua autonomia, como a sua concepção como órgão independente da ONU (embora exista relação de 
cooperação entre as instituições) e a autonomia concedida à promotoria para acionar, por iniciativa própria, independente de provocação, a jurisdição do tribunal (artigo 15.1) (BRASIL, 2002).

Questão que gerou polêmica e dividiu opiniões durante a Conferência de Roma diz respeito à extradição de nacionais. Como muitos Estados, como é o caso do Brasil, vedam esta prática, foi adotado o termo "entrega" na redação do texto do Estatuto, para designar a disponibilização de nacional para julgamento pelo TPI. Assim, criou-se uma distinção entre os termos entrega e extradição (CASELLA; ACCIOLY; SILVA, 2010).

Em suma, podemos afirmar que algumas características essenciais diferenciam o TPI dos tribunais antecessores, quais sejam a complementaridade, a independência, a permanência e a sua vocação universal, que representam a evolução do Direito Penal Internacional e o esforço da comunidade internacional para repreender e punir de forma isonômica os criminosos responsáveis pela prática de crimes de maior gravidade que a afetem.

A não adesão universal ao seu Estatuto de Roma e a falta de mecanismos próprios de caráter coercitivo para obrigar os Estados ao cumprimento de suas determinações, que o tornam inteiramente dependente da cooperação dos Estados, como, por exemplo, no que diz respeito à entrega de seus nacionais para julgamento pela Corte Criminal Internacional, são barreiras que ainda precisam ser transpostas pelo bem da efetividade da instituição.

\section{A QUESTÃO DA COMPETÊNCIA EM RAZÃO DA MATÉRIA}

De acordo com o disposto no artigo $5^{\circ}$ do Estatuto de Roma, a competência do Tribunal em razão da matéria "restringir-se-á aos crimes mais graves, que afetam a comunidade internacional no seu conjunto" (BRASIL, 2002, p. 3). Baseado no que se entendeu, por ocasião da finalização do texto do instrumento constitutivo do TPI, serem práticas criminosas mais graves que merecessem a apreciação daquela corte internacional (CARDOSO, 2012), foram elencadas quatro categorias diferentes de crimes, sendo eles o crime de genocídio, os crimes contra a humanidade, os crimes de guerra e o crime de agressão, para delimitarem o campo de atuação do órgão.

$\mathrm{O}$ crime de genocídio, embora se enquadre na categoria de crimes contra a humanidade, foi destacado isoladamente no artigo $6^{\circ}$ do Estatuto de Roma em virtude de sua relevância e sua definição foi extraída da Convenção para a Prevenção e Repressão do Crime de Genocídio de 9 de dezembro de 1948 (BAZELAIRE, 2004). De acordo com o dispositivo 
legal (BRASIL, 2002), este delito é caracterizado por qualquer ato praticado com intenção de destruir, no todo ou em parte, um grupo nacional, étnico, racial ou religioso, conforme o rol discriminado nas alíneas subseqüentes do artigo. O texto não estabelece restrição temporal (não importando se a prática se dá em tempo de guerra ou paz) e nem limitação quanto a qualquer qualidade do agente (pode ser praticado por qualquer pessoa). Quanto ao elemento volitivo subjetivo, este é indispensável para a configuração do crime, ou seja, o agente deve ter a intenção de alcançar o resultado determinado: destruir, no todo ou em parte, um grupo nacional, étnico, racial ou religioso.

Quanto aos crimes contra a humanidade, estes estão elencados e definidos no artigo $7^{\mathrm{o}}$ do Estatuto de Roma em dez modalidades diferentes (como exemplo o homicídio, extermínio, escravidão, tortura, etc.) além da previsão da alínea "k" que deixou uma porta aberta para a interpretação de outros tipos dentro desta categoria ao mencionar que são crimes contra a humanidade "outros atos desumanos de caráter semelhante, que causarem intencionalmente grande sofrimento, ou afetem gravemente a integridade física ou a saúde física ou mental" (BRASIL, 2002, p. 3-4). Esses delitos caracterizarão crimes contra a humanidade quando cometidos no quadro de um "ataque, generalizado ou sistemático", ou seja, em larga escala com organização e preparação, "contra qualquer população civil", "havendo conhecimento desse ataque" - elemento intencional, volitivo, ou seja, o agente deve planejar o ataque com a intenção de atingir um grande número de civis, objetivando o resultado causado pelas condutas elencadas. É preciso ainda que envolva a prática de múltiplos atos "de acordo com a política de um Estado ou de uma organização de praticar esses atos ou tendo em vista a prossecução dessa política" nos termos o art. 7.2. Os crimes previstos nesta categoria podem ser cometidos tanto em tempo de guerra, quanto em tempo de paz (GARCIA, 2012).

$\mathrm{O}$ art. $8^{\circ}$ do Estatuto de Roma traz o rol extenso dos crimes de guerra, tratando-se dos delitos já previstos na Convenção de Haia de 1907 e nas quatro Convenções de Genebra de 1949 e seus protocolos, que são aquelas violações graves às leis e costumes aplicáveis aos conflitos armados. Nos termos do artigo 8.1 "O Tribunal terá competência para julgar os crimes de guerra, em particular quando cometidos como parte integrante de um plano ou de uma política ou como parte de uma prática em larga escala desse tipo de crimes" (BRASIL, 2002, p. 5). Podem ser punidos pelo TPI até mesmo delitos de caráter não internacional, desde que não se trate apenas de situações de distúrbio e de tensão interna, tais como motins, atos de 
violência esporádicos ou isolados ou outros de caráter semelhante (art. 8.2 alínea "d") (BRASIL, 2002, p. 7).

O crime de agressão foi previsto no art. 5.2 do Estatuto de Roma, mas sua definição ficou para momento posterior à entrada em vigor do TPI (BRASIL, 2002). Isso aconteceu recentemente, em junho do ano de 2010, na Conferência de Kampala, capital de Uganda (CARDOSO, 2012). Esse crime pode ser cometido por pessoa que, estando em condições de controlar ou dirigir efetivamente a ação política ou militar de um Estado (condição especial do agente), planeja, prepara, inicia ou realiza um ato de agressão que por suas características, gravidade e escala constitua uma violação manifesta da Carta das Nações Unidas. Inclui o bloqueio de portos ou da costa marítima de um Estado por forças armadas estrangeiras e a invasão ou ataque por forças armadas de um país contra o território de outro Estado. O TPI poderá exercer sua jurisdição sobre esse crime a partir do ano de 2017 , desde que haja a ratificação de pelo menos 30 Estados-membros (CASELLA; ACCIOLY; SILVA, 2010).

\section{TERRORISMO E DIREITO INTERNACIONAL - BREVE ABORDAGEM HISTÓRICA}

A liberalização do mercado internacional, impulsionada pelo capitalismo que impera no mundo contemporâneo, fez com que indivíduos de diferentes locais do globo passassem a compartilhar, cada vez mais, realidades comuns, que transpõem as barreiras das grandes desigualdades sociais e manifestam-se na democratização de determinados elementos, tais como a moda, hábitos alimentares, hábitos culturais, meios de comunicação, etc.

Paralelamente a este fenômeno da globalização, o mundo viu expandir, de forma também globalizada, as traumáticas práticas de terrorismo por todo mundo. Nas palavras Marco Mondaini, (2004, p. 228; In: PINSK e PINSK, 2004), "beneficiada pela revolução no campo dos transportes de massa e na comunicação eletrônica, a globalização dos mercados passou a ser acompanhada por uma autêntica 'globalização do medo"'.

Não há nem em nível nacional, nem em nível internacional, uma definição precisa do crime de terrorismo em razão da diversidade de condutas de seus agentes e de formas pelas quais pode ser praticado, bem como pela ampla interpretação que o termo comporta. Há, todavia, um consenso quanto à gravidade que esta prática representa e uma preocupação internacional cada vez maior quanto às proporções que ela tem alcançado ao longo dos anos, 
tanto que o tema tem demandado estudos por parte, tanto dos Estados isoladamente, como é o caso do Brasil que possui projeto de lei antiterrorismo (PL n 499/13) tramitando no Senado Federal (BRASIL, 2013), quanto por parte das organizações internacionais, especialmente a ONU, que tem tratado do tema em resoluções e convenções (Resolução 1540/04 - CSNU; adoção da Convenção Internacional para a Supressão de Atos de Terrorismo Nuclear em 2005, dentre outros).

O terrorismo é um método antigo, podendo ser citado como exemplo deste fenômeno, ainda no século XVIII, as práticas radicais do governo revolucionário francês durante o período da ditadura jacobina, que promoveu um verdadeiro "terror de Estado" entre os anos de 1793 e 1794 (MONDAINI, 2004; In: PINSK e PINSK, 2004).

No século XIX, o termo terrorismo chegou a ser entendido, de acordo com o pensamento do francês Pierre Joseph Proudhon e dos russos Miknail Bakunin e Piotr Kropotkin, como uma ferramenta positiva a ser empregada na luta contra a opressão estatal, ou seja, no contexto de uma revolução. Nesse século, o atentado a bomba que vitimou o imperador Alexandre II e assassinato do arquiduque Ferdinando da Áustria, são exemplos de atos de terror praticados por organizações contra o poder do Estado (VISACRO, 2009).

Todavia, foi a partir da Segunda Guerra Mundial, no século XX, que o terrorismo se expandiu consideravelmente e, mais precisamente após os anos 70, passou a assumir aspectos diversos, tais como: "escolha indiscriminada de alvos; arbitrariedade e imprevisibilidade na realização dos atos; uso de métodos de ação extremos e cruéis; indiferença aos códigos morais vigentes; caráter sistemático e continuado" (MONDAINI, 2004, p. 231; In: PINSK e PINSK, 2004).

Os anos 50 e 60 do século passado foram marcados por conflitos de libertação nacional para a independência de países africanos e asiáticos ${ }^{8}$. A partir dos anos 70 a prática se intensificou, destacando-se as ações de extrema-esquerda (com vistas a combater o Estado capitalista e a implantação do comunismo); ações de extrema-direita (para frear avanço de forças socialistas) e estatais (perpetradas pelo próprio Estado para conter grupos sociais e organizações políticas); e ações visando à autonomia estatal (MONDAINI, 2004; In: PINSKY e PINSKY, 2004).

São exemplos de ações terroristas motivadas por posicionamento político-ideológico de extrema-esquerda (MONDAINI, 2004; In: PINSK e PINSK, 2004): 1) os atos praticados pelas Brigadas Vermelhas na Itália, que sob pretexto de luta revolucionária, foi responsável pelo atentado terrorista da Piazza Fontana, em Milão, e pelo seqüestro e assassinato de Aldo 
Moro (1978), líder democrata-cristão, em manifesta intolerância às propostas do "compromisso histórico" acordado entre democratas-cristãos e comunistas; 2) os atos perpetrados pelo Baader-Meinhoff (sobrenome dos principais líderes da organização: Andreas Baader e Ulrike Meinhof) na Alemanha, contra a burguesia capitalista, que vitimaram militares, políticos e empresários, dentre eles o líder industrial alemão Hans-Martin Schleyer.

Marco Mondaini lembra que:

o uso sistemático da tortura e a fabricação constante de "desaparecidos" políticos nos porões de regimes tirânicos, por um lado, e as inúmeras explosões de estações ferroviárias apinhadas de gente comum, por outro, demonstra que o terrorismo não foi privilégio de esquerdistas e nacionalistas extremados. (MONDAINI, 2004, p. 233, In: PINSKY E PINSKY, 2004)

\footnotetext{
${ }^{8}$ Como exemplo podemos citar a guerra para a independência da Argélia, este expediente foi utilizado por ambos os lados do conflito. Na ocasião, militares franceses de extrema direita, integrantes da Organização do Exército Secreto, praticaram atos de terrorismo contra o líder francês Charles de Gaule, por considerá-lo traidor por haver negociado a libertação da Argélia e outros países africanos e explodiram inúmeras bombas na França e na Argélia. (MONDAINI, 2004, p. 230; In: PINSKY E PINSKY, 2004)
}

Nesse contexto, o autor traz à baila o terrorismo estatal, em que o próprio Estado lança mão da prática terrorista para conter grupos sociais e organizações políticas insurgentes e o terrorismo praticado por organizações clandestinas de extrema direita com vistas a frear o avanço de forças socialistas, expedientes comuns às ditaduras militares, frutos dos golpes de Estado nas décadas de 60 e 70, na América Latina (MONDAINI, 2004; In: PINSK e PINSK, 2004).

Quanto ao terrorismo praticado em nome da causa nacionalista, se incluem nesta categoria o terrorismo basco, o terrorismo irlandês e o terrorismo palestino.

O terrorismo basco é fruto das ações do grupo ETA (Euzkadi Ta Askatasuna) criado para lutar contra a ditadura castelhana do general Francisco Franco, mas que, após a morte do ditador e o fim do regime político opressor (1975), intensificou suas ações terroristas durante o período de democracia. Entre 1976 e 1979 o ETA executou cerca de 245 pessoas, e assumiu traços marxistas-leninistas aderindo à luta armada pelo socialismo (MONDAINI, 2004; In: PINSK e PINSK, 2004).

O terrorismo irlandês foi uma prática implementada pelo IRA provisório, grupo formado por dissidentes do IRA (Exército Republicano Irlandês - criado para lutar pela independência da Irlanda do domínio inglês), que, insatisfeitos com opção pela solução diplomática em detrimento da luta armada adotada pelo IRA oficial, se reúne pela continuidade às ações armadas e dá início às práticas terroristas mais sangrentas do período 
compreendido entre o ano de 1969 até o final da década de 70, causando a morte muitas pessoas, através de múltiplas ações como: assassinato de soldados britânicos com tiros na nuca, explosão de bombas em locais públicos e em ruas movimentadas, lançamento de explosivos em bares lotados, etc. (MONDAINI, 2004; In: PINSK e PINSK, 2004).

Com a criação do Estado de Israel para abrigar os judeus refugiados da Segunda Guerra Mundial, na região da Palestina, instaurou-se entre povos judeus e palestinos (agora na condição de refugiados) um conflito que se arrasta até os dias atuais. Durante muitos anos, refugiados palestinos tentaram, sem êxito dada a superioridade militar do adversário, retomar o espaço ocupado pelo Estado de Israel através de confrontos armados convencionais. A pratica de terrorismo contra judeus nasce como uma alternativa encontrada por palestinos para derrotar o inimigo, e é perpetrada por organizações como Frente Popular para a Libertação da Palestina (FPLP), organização radical de orientação política marxista-leninista; Al Fatah, integrante da Organização para a Libertação da Palestina (OLP). Na realidade, os palestinos acabaram internacionalizando o terrorismo, na medida em que passaram a caçar judeus em qualquer lugar, inclusive em outros Estados. No final dos anos 60 e início dos anos 70 empreenderam violentos atentados terroristas como o seqüestro de aeronaves e uso de explosivos em locais públicos, porém o episódio mais traumático aconteceu em setembro de 1972, fruto da ação de um grupo de palestinos que se autodenominou Setembro Negro, que invadiu a vila olímpica de Munique e assassinou 11 atletas judeus (MONDAINI, 2004; In: PINSK e PINSK, 2004).

Interessante perceber que, invariavelmente, as ações nasceram a partir de causas aparentemente justas (com exceção daquelas perpetradas pelo Estado como forma de repressão social e daquelas destinadas a conter avanços democráticos), mas terminaram em atos repudiáveis e injustificáveis, que acabaram por destruir qualquer traço de legitimidade que pudesse haver nestas organizações.

A Revolução Iraniana no final da década de 70, que acarretou a transformação do Irã em uma república islâmica teocrática, é o marco do aparecimento de grupos fundamentalistas islâmicos (como o Hezbollah, o Hamas e a Jihad Islâmica Palestina), que se encarregaram de difundir o terrorismo religioso. (VISACRO, 2009). A partir daí esses grupos passaram a protagonizar o terrorismo internacional, ao mesmo tempo em que o mundo viu emergir um terrorismo doméstico, especialmente norte-americano, através de ações praticadas por cidadãos nativos contra compatriotas, fruto de um fanatismo bélico cultivado ao longo da história daquele país, como, por exemplo, o atentado a bomba em 1995, protagonizado pela 
jovem Timothy McVeigh, que vitimou 168 pessoas ou a chacina praticada por dois jovens adolescentes, num colégio no Colorado em 1999, que matou 15 pessoas. (MONDAINI, 2004; In: PINSK e PINSK, 2004).

Para Marco Mondaini (2004, p. 242; In: PINSKY E PINSKY, 2004), “O terrorismo tornou-se cada vez mais internacional na medida em que o mundo se globalizou em termos econômicos. Dessa forma, o medo também generalizou-se ainda mais ao lado da universalização da intolerância”.

No século XXI o terrorismo passou a se apresentar como um grande problema político e tem marcado incisivamente os conflitos ao redor do mundo. Alguns exemplos que bem representam a ousadia, o aprimoramento, a internacionalização e a institucionalização do terrorismo neste século são o episódio de 11 de setembro de 2001, com a série de atentados contra os Estados Unidos, coordenados pela organização fundamentalista islâmica Al Qaeda, que vitimou milhares de pessoas (MONDAINI, 2004); a explosão simultânea de bombas em três estações de trens em Madri que deixou 198 mortos e 1421 feridos (REDAÇÃO TERRA, 2004); o atentado perpetrado contra a revista "Charlie Hebdo", em Paris, em janeiro de 2015 que terminou com 12 mortos $(\mathrm{G} 1,2015)$; os atentados ocorridos em junho de 2015 na Tunísia, vitimando pelo menos 37 pessoas no ataque a um hotel na cidade de Sousse e no Kuwait, onde 25 pessoas morreram e mais de 200 ficaram feridas após uma explosão em uma mesquita xiita, ataques estes reivindicados pelo grupo terrorista Estado Islâmico 9 .

Para Alessandro Visacro, o terrorismo é uma das práticas que se enquadra no conceito de Guerra Irregular, que por sua vez é por ele definida como "todo conflito conduzido por uma força que não dispõe de organização militar formal e, sobretudo, de legitimidade jurídica institucional. Ou seja, é a guerra travada por uma força não regular" (VISACRO, 2009, p. 12). De acordo com o autor, esta é a forma mais antiga de guerra e a mais comum no mundo contemporâneo, já que organizações terroristas, grupos insurgentes e facções armadas são os atores principais dos conflitos atuais. Visacro ainda alerta para as características que o terrorismo tende a adotar no decorrer deste século:

[...] a ocorrência cada vez mais freqüente e diversificada desse fenômeno; o intenso uso de conexões internacionais, acentuando o seu caráter transnacional; a adoção de estrutura de redes, mais complexas e versáteis, em detrimento das tradicionais organizações verticalmente hierarquizadas; o fortalecimento dos vínculos já existentes com o crime organizado e a associação cada vez mais íntima com o tráfico de armas, o comércio ilegal de drogas e a lavagem de dinheiro; a disseminação de táticas, técnicas e procedimentos, até então restritas às organizações terroristas de vanguarda; o advento de novas e alternativas formas de atuação, como 
o ataque cibernético, por exemplo; a capacidade crescente de ampliar o número de vítimas e, por fim, o acesso a armas de destruição em massa. (VISACRO, 2009, p. 292)

De fato, as perspectivas quanto ao terrorismo são bastante inquietantes e demandam esforços conjuntos da comunidade internacional no sentido de compreender melhor o fenômeno, buscar uma definição e, principalmente, encontrar alternativas para frear seu desenvolvimento e responsabilizar e punir aqueles que fizerem uso deste método/ arma.

\section{A PROPOSTA DE INCLUSÃO DO TERRORISMO COMO COMPETÊNCIA DO TPI, ENQUADRANDO-O NO ROL DOS CRIMES CONTRA A HUMANIDADE.}

Durante os trabalhos preparatórios para constituição do Tribunal Penal Internacional, na Conferência de Plenipotenciários, foi objeto de debate a inclusão do crime de terrorismo no rol de competência da Corte Internacional (OLIVEIRA, 2005).

Inicialmente, o projeto do Estatuto previa dois conjuntos de crimes, sendo o primeiro composto pelos core crimes, ou seja, os crimes primordiais, incluindo as quatro categorias recepcionadas pelo instrumento constitutivo do Tribunal: crime de genocídio, crimes contra a humanidade, crimes de guerra e crime de agressão; e o segundo denominado treaty crimes, composto pelas infrações previstas em diversos tratados internacionais dentre elas, o crime de terrorismo (OLIVEIRA, 2005)

Apesar do esforço de alguns Estados para a inclusão do crime de terrorismo, como foi o caso da Índia, Sri Lanka e Turquia, ele foi preterido pelo Estatuto de Roma, assim como os demais treaty crimes, sob a alegação de que seria difícil definir as infrações e estabelecer um consenso sobre as conceituações, o que retardaria a finalização do instrumento e ainda poderia dificultar a sua adesão rápida e entrada em vigor (VOLZ, 2010).

Convém lembrar, todavia, que a idéia de julgamento do crime de terrorismo por parte de um órgão internacional é anterior mesmo à constituição do TPI. Durante os anos 30, duas propostas de convenções foram feitas à Associação Internacional de Direito Penal, criada em 1924, respectivamente para prevenção, repressão e julgamento do crime de terrorismo por uma corte penal internacional (VOLZ, 2010). Através da convenção de 16 de novembro de 1937, decidiu-se pela criação da Corte Penal Internacional para julgamento dos autores de

\footnotetext{
${ }^{9}$ Grupo terrorista sunita conhecido por suas ações extremas contra a população civil da Síria e do Iraque, como estupros, massacre de cristãos e de xiitas (FERNANDES, 2015)
} 
atos terroristas, porém, tal convenção não chegou a vigorar por falta de ratificações suficientes por parte dos Estados membros (BAZELAIRE, 2004).

Apesar do insucesso quanto às proposições antigas e da não inclusão do crime de terrorismo no rol de competências do TPI, uma janela aberta através do artigo 123 de seu Estatuto nos permite vislumbrar o preenchimento desta lacuna, já que autoriza a revisão do instrumento, a qualquer tempo, para a inclusão de novos delitos (BRASIL, 2002). Nesse sentido, o crime de terrorismo poderia, futuramente, ser inserido como delito à parte na competência do Tribunal.

Uma sustentação mais ousada e que permitiria uma solução imediata para atribuir ao TPI a competência para apreciar o crime de terrorismo, seria integrá-lo ao rol dos crimes contra a humanidade, com os quais se identifica pela definição dessa categoria de crime, hipótese que encontra respaldo doutrinário, como é o caso do raciocínio desenvolvido por Jean-Paul Bazelaire:

\begin{abstract}
Não poderia considerar, por exemplo, que a colocação reiterada de bombas ou lançamento de gases mortais em locais públicos constituem perseguição de um grupo ou de uma coletividade identificável por motivos políticos, raciais ou religiosos? Não é a mesma situação conhecida há tanto tempo pelo País Basco espanhol e pela Irlanda do Norte? Os assassinatos ou o rapto de pessoas públicas seguidos de sua execução estão tão distantes das incriminações consideradas pela CPI? (BAZELAIRE, 2004)
\end{abstract}

Se assim considerarmos o crime de terrorismo, ou seja, uma vez reconhecida sua identidade com os crimes contra a humanidade, em tese, esse crime já poderia ser apreciado pelo TPI, já que o artigo $7^{\circ}$ de seu estatuto, ao prever na alínea " $\mathrm{k}$ " do parágrafo primeiro que se incluirão nesta categoria "outros atos desumanos de caráter semelhante, que causem intencionalmente grande sofrimento, ou afetem gravemente a integridade física ou a saúde física ou mental” (BRASIL, 2002, p. 4), abre uma porta para esta possibilidade.

Fato é que, o caráter transnacional que este delito tem assumido neste século, sendo a sua prática muitas vezes financiada ou mesmo promovida pelos próprios Estados, que por isso obviamente não envidarão esforços para a sua repressão e punição, são situações que exigem que o combate e punição dessa prática não fiquem restritos exclusivamente à competência doméstica, devendo ser apreciados também no âmbito internacional.

\title{
CONCLUSÃO
}

Ao longo da história da humanidade, muitos atos criminosos, praticados normalmente em nome de ideais escusos, aterrorizaram e dizimaram milhares de civis 
inocentes, colocando, por vezes, em risco de extermínio raças ou grupos sociais inteiros. A impunidade dos responsáveis por tais barbáries, em sua grande maioria, foi a representação da mais elevada injustiça e desumanidade.

Nesse contexto, o Tribunal Penal Internacional, fruto de um longo processo de busca pela justiça, representa um importante avanço na segurança jurídica internacional e uma especial evolução do Direito Humanitário Internacional. Algumas características essenciais que o diferenciam dos tribunais antecessores são a complementaridade, a independência, a permanência e a sua vocação universal.

A não adesão universal ao seu Estatuto e a falta de mecanismos próprios de caráter coercitivo para obrigar os Estados ao cumprimento de suas determinações, são barreiras que ainda precisam ser transpostas pelo bem da efetividade da instituição.

Outro ponto que necessita de avanços para tornar o Tribunal Penal Internacional mais eficiente no combate e punição dos graves crimes de relevância internacional é a ampliação de sua competência material para julgamento do crime de terrorismo.

O terrorismo, que é uma prática antiga e que vem se institucionalizando e adquirindo cada vez mais contornos internacionais, vitimando milhares de civis inocentes, é hoje um grande problema político que tem marcado incisivamente os conflitos ao redor do mundo. As perspectivas quanto a essa prática são preocupantes e demandam esforços conjuntos da comunidade internacional no sentido de compreender melhor o fenômeno, buscar uma definição e, principalmente, encontrar alternativas para frear seu desenvolvimento e responsabilizar e punir aqueles que fizerem uso desta arma.

Uma vez que extrapola as fronteiras dos Estados, afetando a comunidade internacional, é de interesse transnacional e a falta de consenso não pode gerar a paralisia dos Estados na busca pelo entendimento e definição que viabilize meios para a sua repressão e punição em nível internacional, inclusive através do Tribunal Penal Internacional.

Uma alternativa imediata e viável seria reconhecer o terrorismo como um crime contra a humanidade, o que seria perfeitamente aceitável devido a sua identificação com a definição dessa categoria de delito e devido à abertura deixada pela alínea " $\mathrm{k}$ " do artigo $7^{\circ}$ do Estatuto de Roma, que permite a extensão do rol de práticas delituosas integrantes da categoria que guardem semelhança com aqueles já discriminados.

Esta é uma atitude que se impõe à comunidade internacional, que tem o dever de agir de forma preventiva, buscando evitar que possíveis episódios futuros acarretem prejuízos irreparáveis à humanidade e quedem impunes, como tantas outras bárbaras ocorrências do 
passado, ou que conduzam os Estados para a adoção de medidas inapropriadas, como o estabelecimento de tribunais de exceção.

\section{REFERÊNCIAS}

AMARAL, J. A. do. Curso de Direito Internacional Público. $4^{a}$ ed. - São Paulo: Atlas, 2008.

BAZELAIRE, J. P.; CRETIN, T. A justiça penal internacional: sua evolução, seu futuro: de Nuremberg a Haia. Tradução de Luciana Pinto Venâncio. Barueri, SP: Manole, 2004. BRASIL. Decreto no 4.388, de 25 de setembro de 2002. Disponível em: <http://www.planalto.gov.br/ccivil_03/decreto/2002/D4388.htm>. Acesso em: 15 mar. 2015.

BRASIL. SENADO FEDERAL. Projeto de lei do senado, No 499 de 2013. Disponível em: <http://www.senado.gov.br/atividade/materia/detalhes.asp?p_cod_mate=115549>. Acesso em: 15 mar. 2015.

CARDOSO, E. Tribunal Penal Internacional: conceitos, realidades e implicações para o Brasil. Brasília: FUNAG, 2012.

CASElla, P. B.; ACCIOLY, H.; SILVA, G. E. do N. e. Manual de direito internacional. $18^{\mathrm{a}}$ ed.- São Paulo: Saraiva, 2010.

COMITÊ INTERNACIONAL DA CRUZ VERMELHA. Org. A Guerra e o Direito.

Disponível em: <https://www.icrc.org/pt/guerra-e-o-direito>; Acesso em: 25/07/2015.

FERNANDES, C. Estado Islâmico - Grupo terrorista. 2015. Disponível em:

<http://www.historiadomundo.com.br/idade-contemporanea/estado-islamicogrupoterrorista.htm> Acesso em: jun 2015.

GARCIA, F. L. M. O Tribunal Penal Internacional: funções, características e estrutura.

Revista Âmbito Jurídico, Rio Grande. ago. 2012, n. 103, XV. Disponível em:

$<$ http://www.ambito-

juridico.com.br/site/index.php/?n_link=revista_artigos_leitura\&artigo_id=12141\&revista_cad erno=16>. Acesso em: 15 mar. 2015.

G1. Ataque em sede do jornal Charlie Hebdo em Paris deixa mortos. São Paulo: 20015 Disponível em: <http://g1.globo.com/mundo/noticia/2015/01/tiroteio-deixa-vitimas-emparis.html>. Acesso em: 15 jul 2015

G1. Atentados terroristas em três países matam dezenas de pessoas. São Paulo: 2015

Disponível em: <http://g1.globo.com/mundo/noticia/2015/06/atentados-terroristas-em-trespaises-matam-dezenas-de-pessoas.html>. Acesso em: 15 jul. 2015

INTERNATIONAL CRIMINAL COURT. About the Court. Disponível em:

$<$ http://www.icc-

cpi.int/en_menus/icc/about $\% 20$ the $\% 20$ court/Pages/about $\% 20$ the $\% 20$ court.aspx $>$. Acesso em 15 jul. 2015 
LEWANDOWSKI, E. R. O Tribunal Penal Internacional: de uma cultura de impunidade para uma cultura de responsabilidade. Disponível em:

<http://www.scielo.br/scielo.php?pid=S0103-40142002000200012\&script=sci_arttext>

Acesso em: 29 abr. 2015.

LIMA, R. M. de; BRINA, M. M. da C. O Tribunal Penal Internacional. Belo Horizonte: Del Rey, 2006.

MONDAINI, M. A globalização do medo. In: PINSKY, J.; PINSKY, C. B. Org. Faces do fanatismo. São Paulo: Contexto, 2004.

OLIVEIRA, C. J. M. de. Os crimes internacionais e o Tribunal Penal Internacional: análise do conceito dos tipos penais do Estatuto de Roma. Disponível em:

<http://www.conpedi.org.br/anais/36/05_1656.pdf〉. Acesso em: 28 abr. 2015.

REDAÇÃO TERRA. Atentados em estações de trem matam 198 em Madri. 2004. Disponível em: <http://noticias.terra.com.br/mundo/noticias/0,,OI278003-EI294,00Atentados+em+estacoes+de+trem+matam+em+Madri.html>. Acesso em: 15 jul. 2015

SANDS, P. (Ed.). From Nuremberg to the Hague. Cambridge: Cambridge University Press, 2003.

UNITED NATIONS. International Criminal Tribunal for the former Yugoslavia. About the ICTY. Disponível em: 〈http://www.icty.org/sections/AbouttheICTY>. Acesso em: 15 jul. 2015.

UNITED NATIONS. International Criminal Tribunal for Rwanda. The ICTR in Brief. Disponível em: <http://www.unictr.org/en/tribunal>. Acesso em: 15 jul. 2015.

VISACRO, A. Guerra irregular: terrorismo, guerrilha e movimentos de resistência ao longo da história. São Paulo: Contexto, 2009.

VOLZ M. B. A cunhagem de uma moeda inédita e singular: o processo de criação do Tribunal Penal Internacional. Disponível em: <http://base.repositorio.unesp.br/handle/11449/93193>. Acesso em 28 abr. 2015. 